\title{
Reinhart Fuchs: \\ Ein mittelalterlicher Kopfdoktor
}

\section{Monika Philippi}

M.A., Mediävistin

«Falsche Doktoren» gibt es in unserem gegenwärtigen Medizinalltag immer wieder. Der Respekt vor wohlklingenden Titeln trägt das Seine zu solchen Fällen bei. Unsere Autorin, eine Mediävistin, hat einen Fall von ärztlicher Titelschwindelei in der mittelalterlichen Literatur entdeckt: bei Reinhart, dem Fuchs.

«Gott behüte mich vor üblen Lügnern, dass sie mir keinen Kummer machen.» Das sagt gerade Reinhart Fuchs, der grösste Lügner von allen, beim Aufbruch zu seinem letzten Abenteuer im gleichnamigen Tierepos des mittelalterlichen Dichters Heinrich des Glîchezâre [1]. Eigentlich jedoch hat der über die Jahrhunderte bis in unsere Zeit als Symbol der Schlauheit geltende Fuchs ein solches Gebet nicht im Geringsten nötig, nicht zuletzt aufgrund geschickt angewendeter Medizinkenntnisse ...

Der Name Reinhart stammt aus dem Altdeutschen und bedeutet so viel wie «der im Rat fest ist» [2]. Was den Fuchs betrifft, so hat dieser seinem Namen zum Zeitpunkt des Gebetes bereits alle Ehre gemacht und sich als jemand erwiesen, dem immer etwas einfällt. Denn er versteht sich meisterhaft darauf, zu bekommen, was er will - und das sind keineswegs nur die Hühner in Nachbars Garten. Seine Feinde lässt er immer wieder schmerzhaft auflaufen, und er schafft es auch, seinen Kopf aus der Schlinge zu ziehen, wenn er aufgrund seiner Betrügereien wieder einmal zum Tode verurteilt wurde. Immer gelingt es ihm, eloquent, durchdacht und erfindungsreich die Köpfe seiner Gegner zu manipulieren; sei es psychologisch, indem er sie glauben macht, was immer ihm nützlich ist, oder physisch, indem er sie dazu bringt, ihren Kopf genau dort hineinzustecken, wo Schlimmes wartet: Der Erzfeind Wolf z.B. giert nach dem Inhalt der füchsischen Bratpfanne. «Dann streck nur deinen Kopf hier herein!», rät Reinhart heimtückisch. Wolf Isengrin steckt also seinen Kopf durchs Küchenfenster, wird schmerzhaft tonsuriert und - wer den Schaden hat, braucht für den Spott nicht zu sorgen - am Ende auch noch als dumm verhöhnt. Bär Brun steckt seinen Kopf in einen Baumstamm, der nach Aussage von Reinhart Honig enthält, und verliert dabei Ohren und Kopfhaut. Dem Kater verspricht der Fuchs fette Mäuse; begierig rennt dieser daraufhin mit dem Kopf zuerst durch die Wand, hinter der er diese Mäuse rascheln hört, und landet damit geradewegs mit dem Hals in der dort ausgelegten Schlinge.

\section{Der Fuchs als Arzt}

Als fulminanter Schlussakt der manipulativen Schachzüge Reinharts verliert gar der König der Tiere selbst seinen Kopf. Dieser leidet unter extremen Kopfschmerzen, als er einen Hoftag einberuft, zu dem auch der Fuchs, unter schärfste Anklage gestellt, vor Gericht geladen wird. Reinhart tritt als Arzt auf und gibt vor, den König heilen zu wollen. Dabei legitimiert sich der eigentlich allen Anwesenden seit langem als Lügner und Betrüger bekannte Schlauberger auf zweierlei Art als Mediziner: Zum einen ist es ihm um das richtige Erscheinungsbild zu tun. "Ganz wie ein richtiger Arzt» trägt er sein bestes Gewand, eine zeittypische Arzt-

\section{Der eitle König akzeptiert den Fuchs begeistert} als Leibarzt.

tasche und behängt sich möglichst sichtbar mit «Behältern voll Nelken und Zimt» sowie vielen unbekannten Arzneikräutern und Gewürzen. Erst dann lässt er sich bei Hofe sehen.

Zum anderen gibt sich der Fuchs gebildet mit einer undurchsichtigen Erwähnung der Mediziner-Hauptstadt des 12. Jahrhunderts: Salerno. Dort befindet sich die aus seiner Sicht (die Dichtung wurde gegen Ende des 12. Jh. verfasst) älteste und renommierteste Universität. Ein solches auswärtiges Diplom (das Reinhart im Übrigen gar nicht vorzuweisen braucht - allein die Erwähnung der Stadt genügt) liefert im deutschen Mittelalter keinerlei Grund zum Misstrauen, sondern ist vielmehr Kompetenzbeweis. Denn zumindest im deutschen Sprachgebiet wird Medizin erst vom Anfang des 15. Jahrhunderts an obligatorischer Bestandteil der Universitätslehrpläne. Bis dahin erwerben deutsche 


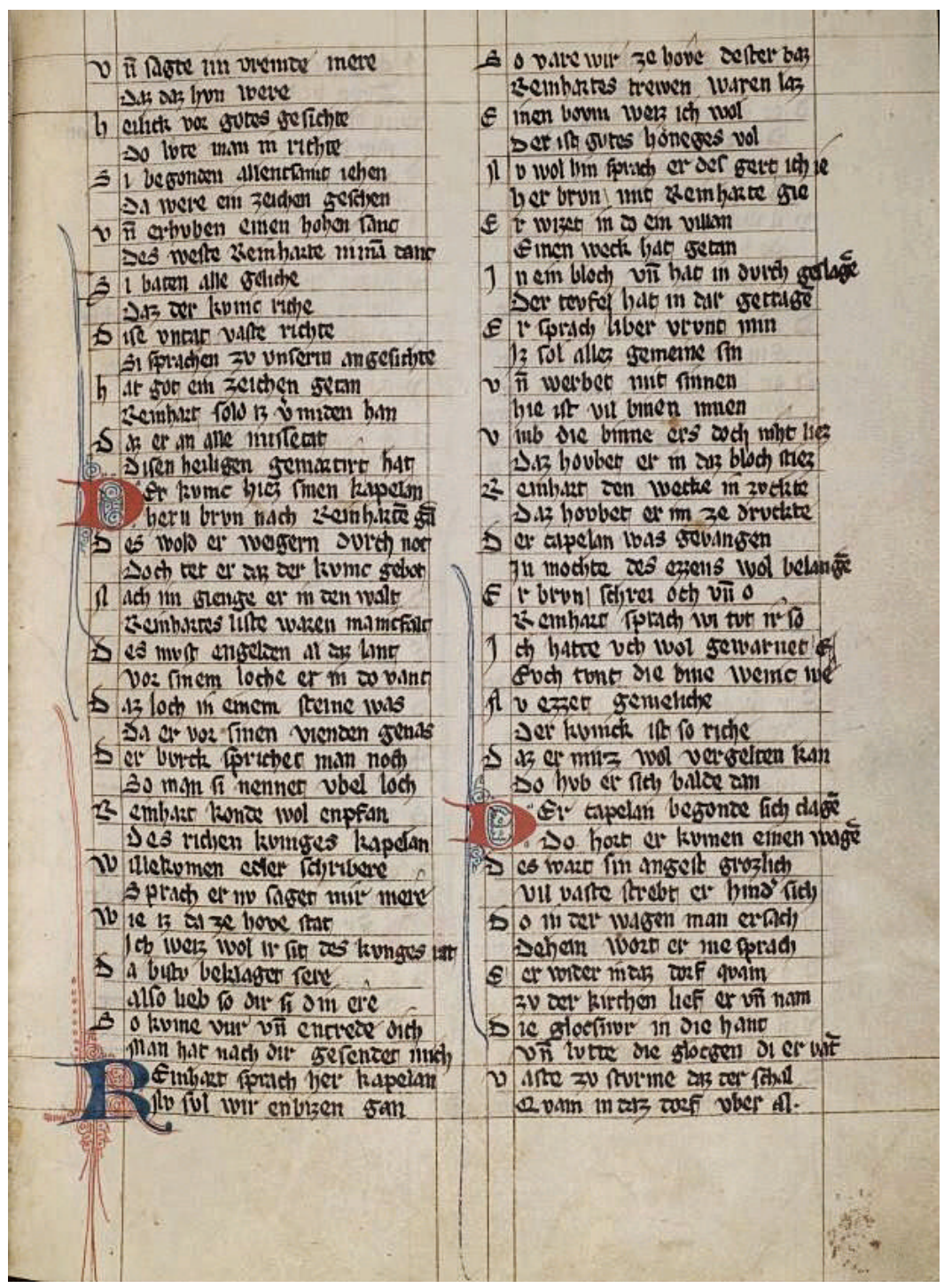

Seite aus der Heidelberger Märensammlung, einer der Handschriften, in der Heinrichs Tierepos überliefert ist. Handschrift, 14. Jahrhundert; Heidelberg, Cpg 341, 177r. Quelle: Wikipedia.
Korrespondenz:

Monika Philippi, M.A.

Gruthweg 30F

CH-4142 Münchenstein

monika.philippi[at]unibas.ch
Ärzte ihre Ausbildung in Italien und Frankreich. Als Heinrich sein Fuchs-Epos schreibt, zählt etwa Maurus von Salerno (um 1130-1214) zu den bekannteren Ärzten. Seine Abhandlungen finden bereits zu seinen Lebzeiten internationale Verbreitung. Fuchs Reinhart beruft sich aber vorsichtshalber nicht auf eine Koryphäe; er lässt den kranken König stattdessen von einem Meister Bendin grüssen, der völlig unbekannt ist. So kann ihm Reinhart versichern, Bendin sei um Ansehen und Wohlergehen des hiesigen Königs sehr besorgt. Eine solche Referenz, die nur der Fuchs allein kennt, wird dem Gesagten kaum widersprechen. Und indem Reinhart in gelassener Selbstverständlichkeit eine völlig unbekannte Person benennt, spiegelt er universitäres Insiderwissen vor. Die Taktik geht auf, der eitle König akzeptiert den Fuchs begeistert als Leibarzt und befolgt alle seine Anordnungen.

\section{Die Rache des Arztes/Fuchses}

Daraufhin nützt der Fuchs allerhand Brimborium dazu, sich an all jenen zu rächen, die ihm stets übelgesinnt waren. Unter der Vorgabe, es sei zur Heilung ihres Herrn und Königs unbedingt nötig, müssen Kater, Wolf, Bär und weitere Ankläger des Fuchses zu angeblich medizinischen Zwecken Teile ihrer Haut hergeben: «einem alten Wolf, wenn Ihr ihn findet [sollt] Ihr die Haut abziehen lassen; und dazu müsst Ihr noch ein Bärenfell haben», «Eine Mütze aus Katzenfell ist ausserdem noch nötig». Die Henne, die schon immer vor dem Fuchs gewarnt hat, wird gar komplett zum Arznei-Braten, lecker angerichtet mit Speckstreifen vom Eber. Verdeckt durch all diesen Aufwand «heilt» der Fuchs den König zunächst vom Kopfschmerz. Das ist denkbar einfach und ohne medizinische Kenntnisse zu bewerkstelligen: Er entfernt eine randalierende Ameise aus dessen Gehörgang. Diese hat er nicht etwa mittels ausgefeilter Diagnosemethoden als Ursache für die monarchische Migräne identifiziert. Er hat bereits im Vorfeld unbemerkt beobachtet, wie sie in den königlichen Kopf hineingekommen ist. Zum Abschluss der komplizierten Bade- und Diätkur erhält der König vom Fuchs einen Heiltrunk, doch erkennt er ihn erst im Todeskampf als Giftbecher.

«Ich weiss genau, dass Eure ganze Klage ihren Ursprung im Kopf hat», spricht der Fuchs am Anfang der Heilkur zum Staatsoberhaupt der Tierwelt. Dessen Haupt zerfällt am Ende des füchsischen Medizin-Exkurses in vier Teile und das Königreich der Tiere in potentielle Anarchie. Das zeigt, dass ein Fuchsdoktor in der Lage ist, Köpfe sogar postmortal zu manipulieren und mit den physischen Köpfen auch die Staatsund Gesellschaftsordnung auf den Kopf zu stellen.

Literatur

1 Heinrich, der Glîchezâre. Reinhart Fuchs. Hg. u. übers. von KarlHeinz Göttert. Stuttgart: P. Reclam; 1976

2 Kluge F. Etymologisches Wörterbuch der deutschen Sprache. 24. durchges. u. erw. Aufl. Hg. u. bearb. v. Elmar Seebold. Berlin/New York: De Gruyter; 2002. S. 754.

Um 1192 schuf ein Elsässer mit Namen Heinrich sein, soweit wir wissen, einziges Werk, das erste deutschsprachige Tierepos Reinhart Fuchs. Heinrich trägt auch den Beinamen «der Glîchezâre». Dies geht entweder auf einen früheren Übersetzungsfehler zurück, der das Attribut des Fuchses (Gleissner, Spielmann) auf seinen Autor übertrug. Oder aber der Beiname ist eine Schöpfung des Autors selbst, ähnlich wie sich auch der mittelalterliche Dichter "der Stricker» nach seiner Tätigkeit - der Wortweberei - nennt. Ausser diesen Eckpunkten und seiner anti-staufischen politischen Einstellung, die im Reinhart Fuchs durchklingt, bleibt die Person Heinrich der Glîchezâre bis heute ein Rätsel. 